\title{
Problematizando o livro didático: uma análise da obra "Fundamentos de Filosofia" de Gilberto Cotrim e Mirna Fernandes
}

\author{
Questioning the textbook: an analysis of the work "Fundamentos de \\ Filosofia" by Gilberto Cotrim and Mirna Fernandes
}

\section{Thiago Coelho Silveira}

Professor doutor no Instituto Federal do Maranhão, Presidente Dutra, MA, Brasil. silveiratc@hotmail.com - http://orcid.org/0000-0003-0839-0165

Recebido em 20 de maio de 2020

Aprovado em 07 de abril de 2021

Publicado em 25 de maio de 2021

\section{RESUMO}

Este trabalho tem por objetivo analisar o livro didático "Fundamentos de Filosofia" de autoria de Gilberto Cotrim e Mirna Fernandes, com um olhar mais específico sobre o uso das imagens na constituição da obra. A pesquisa justifica-se, dentre outros motivos, pela necessidade de ampliação dos estudos acerca do livro didático de Filosofia enquanto ferramenta capaz de aproximar os jovens do Ensino Médio da disciplina durante o processo formativo. Para tanto, utilizou-se da metodologia da pesquisa documental, no que diz respeito à busca de informações acerca dos autores, e bibliográfica, de forma a conduzir a análise acerca da obra e do referencial teórico pertinente ao tema. Como resultado, apresentamos uma contribuição para o quadro geral da produção acadêmica na área de Ensino de Filosofia, colaborando para alçar um maior espaço para os estudos que tomam as ferramentas pedagógicas, como o livro didático, enquanto objeto de análise.

Palavras-chave: Ensino; Filosofia; Livro didático.

\section{ABSTRACT}

This work aims to analyze the textbook "Fundamentos de Filosofia" written by Gilberto Cotrim and Mirna Fernandes, with a more specific look at the use of images in the constitution of the work. The research is justified, among other reasons, by the need to expand studies on the Philosophy textbook as a tool capable of bringing young people from high school to the discipline during the formative process. For that, it was used the methodology of the documentary research, regarding the search for information about the authors, and bibliographic, to conduct the analysis about the work and the theoretical framework pertinent to the theme. As a result, we present a contribution to the general framework of academic production in Teaching Philosophy area, collaborating to raise a greater space for studies that take pedagogical tools, such as the textbook, as an object of analysis.

Keywords: Teaching; Philosophy; Textbook. 


\section{Introdução}

Nas últimas décadas, especialmente a partir de 2008, tem sido produzido um número significativo de pesquisas em torno do ensino de Filosofia, uma vez que aquele ano marca o retorno da disciplina para o currículo do ensino médio como componente curricular obrigatório. Tomamos esse período como marco para apontar uma ampliação qualitativa e quantitativa das pesquisas realizadas, o que não quer dizer que no período anterior o tema não viesse sendo discutido com a acuidade necessária. Pelo contrário, foi justamente a existência dessas vozes que possibilitaram um debate crescente sobre a importância da Filosofia para a formação dos jovens, possibilitando o seu retorno.

Nesse ínterim, os estudos desenvolvidos questionam o papel do professor, a contribuição da Filosofia para a formação de jovens, a necessidade ou não de livros didáticos, quais conteúdos devem ser ministrados, quais metodologias mais apropriadas, dentre muitas outras questões pertinentes ao tema. Assim, este trabalho ${ }^{1}$ se direciona para o uso que o livro de Filosofia faz das imagens no processo de tentar aproximar o aluno das discussões propostas.

No âmbito do Instituto Federal do Maranhão (IFMA), essa discussão se faz cada vez mais necessária, uma vez que percebemos um número limitado de trabalhos de pesquisa aprovados nos editais institucionais que tomam a Filosofia como campo e objeto de estudo e reflexão. A importância da pesquisa se dá ainda pela possibilidade de contribuir para a formação de jovens dotados de referenciais teóricos e preparados para uma leitura de mundo que toma o respeito e a empatia como princípios para a construção de uma vida cidadã plena.

A pesquisa desenvolvida teve como objetivo geral analisar o uso das imagens no livro didático "Fundamentos de Filosofia" de autoria de Gilberto Cotrim e Mirna Fernandes (2016). Trata-se de uma análise bibliográfica, visto que não se estabeleceu, nesse momento, a problematização dos usos que os professores fazem do livro na sala de aula. Em suma, nossos interesses se direcionaram para o processo de constituição de elementos pedagógicos no cerne da produção do conteúdo do livro didático de filosofia. 
Para subsidiar metodologicamente o trabalho, partimos das concepções de pesquisa bibliográfica apresentadas por Gil $(1999,2002)$. Dessa forma, a pesquisa assim está definida, seja pelo próprio objeto de estudo, o livro didático de Filosofia, seja pelas técnicas utilizadas que consistiram na busca de referenciais teóricos para subsidiar as análises realizadas, sobretudo em torno do eixo central do trabalho que é o ensino de Filosofia.

Ainda, segundo os indicadores apontados por Gil (1999, 2002), podemos afirmar que este trabalho também possui caráter de pesquisa documental, na medida em que buscamos informações sobre o percurso formativo-instrucional dos autores com o intuito de compreender as bases pedagógicas envolvidas no contexto de produção da obra. No tocante, especificamente, à análise dos usos das imagens, tomamos como amostra os cinco primeiros capítulos, uma vez que se mostraram suficientes para compreendermos a lógica de sua disposição e articulação ao conteúdo.

Nesse sentido, a discussão que segue busca fomentar o campo de reflexão sobre o ensino de Filosofia, sobretudo em um momento em que a implantação da Base Nacional Comum Curricular (BNCC), etapa do Ensino Médio (BRASIL, 2018), tende a impor um novo olhar para a operacionalização dos conhecimentos do campo filosófico e para a produção de materiais didáticos. Assim, é preciso conhecer os materiais que possuímos hoje para podermos repensar os materiais que essa nova perspectiva curricular ensejará.

\section{O livro didático de Filosofia entre textos e imagens}

Em meio a um contexto de discordâncias e incertezas, o ensino e aprendizado da Filosofia no âmbito educacional assume importância na educação de jovens no Brasil. A disciplina voltou a fazer parte do currículo escolar desde 2008 na condição de componente obrigatório para os anos do Ensino Médio através da Lei n. 11.684/2008. Inclusão essa que, aborda Carminati (2013), ocorreu após amplo debate construído desde os anos finais da Ditadura Militar no Brasil e à medida que o país se abriu ao processo de redemocratização. 
Foram, assim, quase 4 (quatro) longas décadas de ausência da disciplina no currículo brasileiro, cujo retorno implicou em uma disputa de espaço com outros componentes curriculares que já haviam ocupado o lugar deixado pela Filosofia quando de sua exclusão. Passada uma década de seu retorno, vimos as tratativas da reforma educacional de 2017 novamente colocar em xeque o seu lugar e a sua importância, o que só foi possível garantir após ampla mobilização social.

Assim, se pudermos falar que saímos vitoriosos pela referência no texto legal ao ensino da Filosofia, não podemos dizer o mesmo sobre a forma em que essa permanência foi garantida. A lei $n^{\circ} 13.415 / 2017$, que promove uma reforma no Ensino Médio e altera a Lei de Diretrizes e Bases da Educação, lei 9.394/1996, garante a obrigatoriedade na condição de "estudos e práticas", gerando um cenário de incertezas sobre a existência da Filosofia como componente curricular com caráter de disciplina.

A preocupação, então, é de que a Filosofia seja secundarizada no âmbito do currículo escolar, podendo ser fragilizada sob o rótulo de projetos integradores, rodas de conversas, oficinas, dentre outras múltiplas dinâmicas que poderão ser adotadas. Logo, a crítica não se dá pela proposição de um currículo que seja composto por outros elementos além das disciplinas, mas pela possibilidade de um ensino fragmentado e que não leve em consideração a sistematização que o conhecimento filosófico demanda ao longo da sua operacionalização nas aulas de Ensino Médio.

A individualidade da Filosofia como disciplina, por outro lado, não implica em renunciar a uma abordagem interdisciplinar, no campo do que a BNCC intitula de Ciências Humanas e Sociais Aplicadas, mas também não perdemos de vista que a emergência de projetos interdisciplinares, que o sejam apenas no nome, pode servir de cortina de fumaça para mascarar o silenciamento da disciplina, pavimentando o caminho para sua posterior exclusão.

A Filosofia permite que os alunos se apropriem de ideias e de uma postura crítica relevante para sua formação e atuação dentro e fora da sala de aula, tornando-os capazes de refletir e distinguir sobre o certo e o errado, o falso e o verdadeiro. Essa habilidade é essencial atualmente, sobretudo diante do cenário de vivermos bombardeados por 
informações falsas veiculadas pelas redes sociais e por veículos de imprensa não comprometidos com o Estado democrático de direito.

No âmbito escolar, o livro didático de Filosofia vem ocupando um papel relevante como ferramenta pedagógica, muito embora possamos perceber diferenças drásticas na abordagem da disciplina e na estruturação dos conteúdos por diferentes autores e editoras. De fato, o recente reingresso da Filosofia no currículo, como apontamos, implica em um processo de amadurecimento das propostas que, por sua vez, incidem diretamente sobre a produção destes materiais.

Franco e Felício (2011) nos lembram que, para Nietzsche, a utilização de livros didáticos é de suma importância para o aprendizado, mas ao mesmo limita-o por não deixar que o pensamento seja livre para obter seus próprios ideais e para um pensamento dogmático. Partindo dessa concepção, os autores discutem o papel do livro didático em contraposição àquilo que Nietzsche propunha, chegando a afirmar que a adoção desse material seria problemática na medida em que isso leva à substituição da leitura dos clássicos pelos compêndios enciclopédicos.

Neste aspecto, somos levados a discordar dos autores. Acreditamos no potencial do livro didático como ferramenta importante nas aulas de Filosofia, no sentido de que eles possibilitam uma maior aproximação dos alunos a temas a princípio distantes da realidade em que se encontram, mas que podem mostrar uma ótica diferente a partir do processo de transposição didática. Se pensarmos na realidade econômica e social dos alunos da rede pública do país, encontraremos muitos outros motivos para defender a existência destes materiais, os quais muitas vezes são a única fonte de contato com a Filosofia que estes sujeitos têm acesso na forma de livros financiados pelo Programa Nacional do Livro Didático (PNLD).

Assim, antes de o livro didático ser visto como uma ferramenta que engessa o ensino e o acesso ao conhecimento filosófico, o vemos como um mecanismo de aproximação, desde que utilizado de maneira apropriada. Ampliando essa discussão, Incontri e Bigheto (2009) apontam para o desafio de entender a importância do pensamento do jovem sobre a Filosofia e vislumbrar o seu entendimento sobre esta, para 
que se compreenda a formação desses indivíduos. Dessa maneira, concordamos com estes autores quando afirmam que a Filosofia é uma necessidade do ser humano, tendo em vista sua condição de ser pensante, o que em si, denota a relevância da disciplina para a formação no Ensino Médio.

Além disso, e pensando um pouco sobre a questão do uso do livro didático, os autores questionam se a cristalização do conteúdo no livro engessa ou facilita o processo do exercício do filosofar por parte dos discentes. A resposta dada nos parece ser mais apropriada, pois os autores apontam para um meio-termo quando dizem:

É preciso mostrar, sobretudo ao adolescente e ao jovem, que a Filosofia tem
perguntas e que procura respostas a respeito de problemas e situações que
são sempre atuais, que Ihes tocam de perto. [...] O grande desafio, que
devemos enfrentar, portanto, é o de atingir uma justa medida entre a história
da Filosofia e a sua tematização; entre a tradição e a possibilidade de
filosofarmos hoje. (INCONTRI; BIGHETO, 2009, p. 31)

A justa medida, a nosso ver, é o ponto de equilíbrio entre o uso do livro didático e o uso de outros materiais, de natureza bibliográfica ou não, no universo das aulas de Filosofia. Não estamos dizendo que esta seja uma tarefa fácil, mas percebemos ser um desafio que tanto o professor como os autores dos livros didáticos precisam enfrentar a fim de tornar a disciplina cada vez mais significativa para os jovens.

Incontri e Bigheto (2009) apontam, assim, para a tarefa do ensino de Filosofia enquanto ensino do filosofar, tendo em vista que, por trás do livro didático, existe um professor que é peça chave no estímulo ao pensamento crítico dos discentes, ajudandoos a perceber o quanto o ato de filosofar é libertador e transforma o olhar a partir de uma visão de mundo holística.

Para tanto, o livro didático de Filosofia precisar colocar o jovem em contato com os textos filosóficos em sua construção original, pois, como conta Oliveira (2004):

[...] toda exposição das ideias de outrem não deixa de estar impregnada pela visão de mundo do expositor, a ausência de confronto entre a fala original do filósofo e a paráfrase feita pelo autor do livro faz que o leitor (professor, leigo ou aluno) fique preso a uma única versão daquele pensamento, considerada como palavra final e indiscutível. (OLIVEIRA, 2004, p. 2) 
Dessa forma, um bom livro didático de Filosofia seria aquele que pode apresentar a perspectiva do autor em constante diálogo com os filósofos sobre os quais se está tratando em cada capítulo. A abordagem proposta reside justamente no princípio de encontrar o ponto de equilíbrio sobre o qual discutimos, permitindo que professor e aluno possam lidar com uma leitura menos árida a partir da discussão do autor, mas também compreender a riqueza que os textos filosóficos originais possuem em sua construção original.

Sobre essa tarefa, Oliveira (2004) problematiza a questão da seleção dos conteúdos e dos filósofos sobre os quais o livro didático trata, lembrando que toda seleção ocorre a partir de critérios. Por mais objetivos que estes pareçam, carregam a visão de mundo daquele que seleciona e daquele que elencou os critérios, sujeitos estes que, por vezes, são a mesma pessoa.

Em síntese, o autor enfatiza que não podemos deixar de entender a posição do autor por trás da obra que constrói, impondo sua visão ao público leitor (professores e discentes). Isso permite julgar até que ponto está sendo dada uma contribuição no sentido de formar o aluno para uma crítica racional da sociedade, pautada em princípios éticos e de cidadania. É preciso ter em mente que a formação de cidadãos capazes de analisar criticamente a realidade que os cerca é uma tarefa basilar da Filosofia e das demais Ciências Humanas e Sociais Aplicadas.

Nesse sentido, cabe aqui retomar as palavras de Carminati, quando diz:

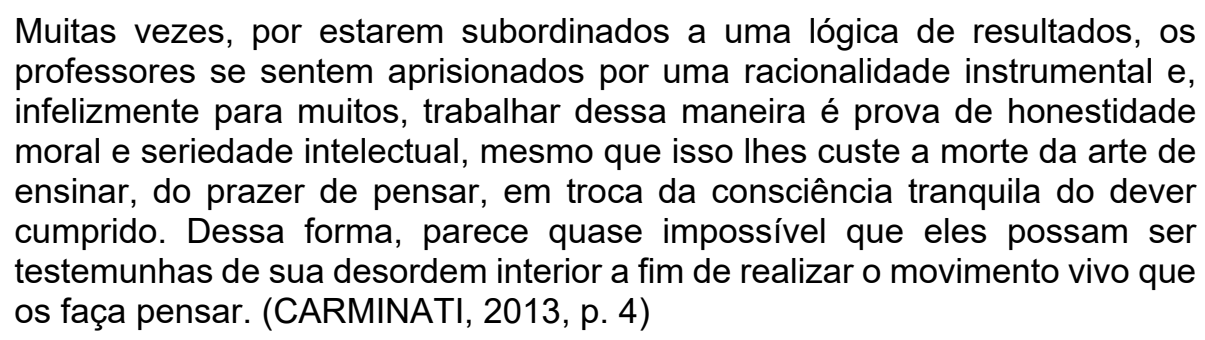

O autor claramente faz uma crítica à subordinação dos professores a uma racionalidade instrumental cada vez mais presente nas escolas, a qual os submete a uma lógica de busca de resultados quantitativos que, em tese, atestariam sua eficiência. No Ensino Médio, isso se dá de maneira muito clara por meio da cobrança da família e da 
própria escola para que os alunos provem que o ensino ministrado foi eficiente a partir de seus resultados nos exames de acesso ao ensino superior das universidades do país.

Em certa medida, essa racionalidade instrumental recai também sobre o autor do livro didático, uma vez que um livro bom seria aquele que, mais do que proporcionar experiências filosóficas, daria conta de indicar conteúdo e possibilidades de resoluções de questões que ajudem os alunos a ingressar no ensino superior. Assim, não é incomum que apareçam seções ao final dos capítulos das obras com questões de exames vestibulares e orientações específicas para o docente utilizá-las, o que foi possível perceber na obra "Fundamentos de Filosofia". Em geral, são questões contextualizadas que buscam verificar tanto a aprendizagem de conceitos filosóficos específicos como a sua aplicação no cotidiano.

Nesse cenário, corre-se o risco de se perder de vista a totalidade e levar o professor a enfatizar mais os aspectos particulares do que o todo no processo pedagógico, sobretudo, a partir da condução dos objetivos do ensino, dificultando a abstração e a compreensão das relações entre os objetos em estudo. Tal cenário pode levar a uma interpretação fragmentada da realidade, visto que o conhecimento é apresentado de uma forma cada vez mais compartimentada, em partes desconexas umas das outras, como destaca Carminati (2013).

Para mudar essa realidade, faz-se de suma importância que o professor assuma uma postura ativa no que concerne à sua prática no ensino de Filosofia. Não se pode esperar que a Filosofia seja neutra, mas sim acreditar no seu potencial de contribuir para uma prática pedagógica emancipadora. Por um longo período da história brasileira, a Filosofia esteve fora do currículo e há menos de duas décadas ela passa a ser disciplina por meio de leis sancionadas e vigentes, mas a dificuldade de compreendê-la em sua significação e contribuição faz com que seu lugar seja frequentemente questionado.

Desse modo, esta pesquisa se direcionou para uma análise mais detalhada da obra de Cotrim e Fernandes (2016) à luz do referencial teórico aqui discutido. Para proceder a esta análise, foram selecionados cinco capítulos do livro para leitura e fichamento do uso das imagens, que se constituem no foco de nossa atenção. Embora as imagens presentes 
na obra não possam ser aqui reproduzidas, o processo de pesquisa empreendido permitiu colher dados suficientes para as considerações tecidas.

A etapa de pesquisa documental se dirigiu à consulta da base de currículos da Plataforma Lattes para fazermos uma análise do percurso formativo dos autores da obra, tendo sido encontrado o perfil de ambos com datas de atualização entre março e maio de 2020. Gilberto Vieira Cotrim possui graduação em Direito pelo Centro Universitário das Faculdades Metropolitanas Unidas (FMU), em Filosofia pela Universidade de São Paulo (USP) e em História pela mesma instituição. Possui ainda mestrado em Educação, Arte e História da Cultura pela Universidade Presbiteriana Mackenzie (MACKENZIE). Em seu currículo, consta a publicação de 7 (sete) obras, em sua maioria livros didáticos ou de cunho educativo ligados a questões sobre a cidadania. Por sua vez, o perfil de Mirna Gracinda Fernandes aponta que a autora é graduada em Filosofia pela USP e atua no mercado editorial de livros didáticos desde 1986, trabalhando junto às principais editoras do ramo no país, tais como: Nacional, Três, Moderna, Saraiva, Ática e Scipione. No sítio eletrônico pessoal da autora, consta ainda a informação de sua atuação como consultora na área de educação e meio ambiente (FERNANDES, 2020).

Dessa maneira, as informações coletadas permitem verificar que os autores da obra aqui em análise possuem larga experiência na produção de livros didáticos. No caso de Cotrim, essa experiência se estende ao campo da cidadania e da História, sendo um autor amplamente reconhecido pela qualidade dos livros que produziu. Não à-toa, sua dissertação de mestrado foi direcionada para a análise das representações de D. João VI em livros didáticos e em uma produção fílmica. Pelo que pode ser percebido, as vivências profissionais dos autores se direcionam para o reconhecimento da produção artística, que, em nossa análise, se direciona para as imagens reproduzidas na obra, como algo positivo no universo da produção de livros didáticos.

As informações documentais permitem ainda vislumbrar a inserção dos autores em meio às principais editoras de livros didáticos do país, as quais contam com amplas equipes de trabalho. Desse modo, a obra ganhou destaque no PNLD dos últimos triênios, sendo adotada em escolas de Ensino Médio de todo o país. 
A análise do conteúdo revela que o uso das imagens é um elemento marcante na obra. Os capítulos são iniciados por uma imagem que ocupa o espaço de duas páginas, servindo também de plano de fundo da apresentação do conteúdo. Em seguida, é apresentada uma historieta que tem como objetivo levar o aluno a refletir sobre o assunto abordado, inclusive usando de estratégias de aproximação com o cotidiano. Aqui novamente as imagens ilustrativas se fazem presentes. Os capítulos, assim, são pensados para operar o lúdico e direcionar o questionamento desde suas primeiras páginas, estimulando o desenvolvimento da reflexão pela abstração. Dada a natureza do conhecimento filosófico, aprimorar a habilidade de compreender conceitos abstratos é tarefa primordial do ensino de Filosofia.

Ao longo dos capítulos, as imagens são presença marcante, aparecendo em quase todas as páginas. A análise permitiu vislumbrar alguns aspectos positivos a respeito do uso que é feito delas. Primeiro, as imagens ajudam a tornar a leitura menos cansativa, uma vez que contribuem para uma melhor visualidade do texto. Segundo, as imagens ilustram o conteúdo, mas não se limitam a essa função, permitindo que, pela leitura das legendas, os discentes tenham acesso a informações complementares. Terceiro, em muitos casos as imagens aparecem associadas a fragmentos de textos filosóficos que, tanto colocam o aluno em contato com a escrita original dos principais autores citados no capítulo, como permitem uma interpretação intertextual entre linguagem escrita e imagética. Quarto, as imagens aparecem como elemento dos exercícios propostos, associando a interpretação dessas ao exercício do pensamento filosófico. Por último, consideramos que as imagens permitem ampliar o caráter interdisciplinar dos conteúdos, na medida em que permitem um diálogo com a arte e, através desta, como conteúdos e informações que facilmente se conectam a outros campos do saber, tais como a História, Geografia, Ciências Sociais e Psicologia.

Outro aspecto positivo é a presença de um "Manual do Professor", que não se limita apenas a propor uma operacionalização do livro didático, mas aponta os pressupostos pedagógicos da obra, além de uma variedade de caminhos possíveis que podem ser seguidos pelo docente. Dessa maneira, os autores reconhecem que o livro didático é um 
"objeto complexo, que apresenta diversas facetas" (COTRIM; FERNANDES, 2016, p. 413), na medida em que é uma obra editorial que não depende exclusivamente dos autores em sua concepção, mas de uma diversidade de profissionais, além de estar sujeita aos condicionantes de mercado, e não é neutra, ao passo que também se pretende como obra educativa que fará parte do cotidiano de alunos e professores.

No tocante à presença das imagens na obra, ainda se faz relevante destacar o posicionamento dos autores ao destacarem que o docente pode enriquecer sua atuação propondo o diálogo entre a iconografia presente no livro e outras representações existentes. Desse modo, o olhar do aluno poder ser ampliado e enriquecido, mas sem necessariamente negar o conteúdo do livro em si. Dessa maneira, os autores propõem o seguinte passo a passo no uso das imagens:

\begin{abstract}
observação e análise - etapa de contato com os diversos elementos ou aspectos iconográficos que constituem a obra em questão - mídia, cores, formas, texturas, cenário, personagens, vestuário, expressões corporais, gestos, emoções retratadas, símbolos etc. - e sua identificação;

contexto e finalidade - sempre que possível e desde que pertinente, é desejável que se reconstitua o contexto em que a obra foi produzida e sua finalidade, procurando identificar as intenções do artista ou daquele que o contratou para sua realização;

interpretação - momento em que se expressa a destreza interpretativa, de reunião dos diversos elementos explícitos e implícitos da obra, buscando identificar a intenção do autor, sua visão, sua mensagem e conferir um sentido a essa imagem. Dependendo da obra, esse sentido pode ser consensual, porém há sempre margem para leituras particulares, derivadas das experiências e percepções de cada um ou relacionadas com a habilidade para chegar às camadas mais profundas de uma imagem e seu simbolismo; problematização - etapa que constitui a leitura filosófica propriamente dita, pois procura reconstruir criticamente a interpretação alcançada da imagem, seus pressupostos e os problemas. (COTRIM; FERNANDES, 2016, p. 423).
\end{abstract}

Nesse sentido, nota-se que as imagens são pensadas como elemento importante para o desenvolvimento de uma leitura filosófica a partir dos temas centrais discutidos nos capítulos. Longe de se restringir à ilustração, elas podem servir de base para a discussão empreendida pelo docente, enriquecendo a atuação em cenários escolares em que outros recursos estão frequentemente indisponíveis. 
Em trabalho anterior, já apontávamos para a importância do uso das imagens e das recomendações fílmicas apresentadas em outro livro didático de Filosofia (SILVEIRA, 2015). Desse modo, seja na obra de Marilena Chauí (2013) ou nesta que analisamos aqui, vimos que os autores enfrentam o desafio comum de transpor o conhecimento filosófico para uma linguagem mais acessível para o público do Ensino Médio.

Portanto, a pesquisa aqui empreendida permite afirmar que as imagens podem ser uma estratégia eficiente para a composição de livros didáticos de Filosofia, desde que não sejam utilizadas como mero recurso ilustrativo. A composição da obra de Cotrim e Fernandes (2016) nos parece ser um exemplo interessante de como a discussão filosófica, que precisa ser realizada com os jovens do Ensino Médio, tende a ser mais atraente quando usa as imagens como elementos discursivos.

\section{Considerações Finais}

O ensino de Filosofia é um campo de estudos que precisa ser aprofundado, sobretudo em tempos como os atuais, em que o papel da disciplina na educação básica vem sendo questionado. É preciso vigilância constante para evitarmos retrocessos, tal como foi necessário durante a edição da reforma educacional de 2017, assim como precisaremos manter durante o processo de reformulação dos currículos das escolas e redes de ensino em função tanto da reforma como da implantação da BNCC.

A pesquisa, cujos resultados foram aqui apresentados, se constitui como uma contribuição para o fortalecimento dessa área, chamando atenção para o livro didático como ferramenta de trabalho docente, sendo esta, muitas vezes, a única que os professores e seus alunos têm acesso. Problematizar a estrutura desses materiais e os recursos que a obra utiliza contribui, assim, para a sua constante melhoria.

Dessa forma, destacamos as potencialidades do uso das imagens no âmbito do livro didático de Filosofia, alertando para o potencial pedagógico que os docentes poderão explorar. Os próximos anos anunciam muitos desafios para a Filosofia no Ensino Médio, 
diante da implantação da BNCC, sendo importante que cada vez mais problematizemos as ferramentas que são colocadas à disposição da comunidade escolar, tal como o fizemos aqui.

\section{Referências}

BRASIL. Conselho Nacional de Educação. Resolução CNE/CP n 4, de 17 de dezembro de 2018. Institui a Base Nacional Comum Curricular na Etapa do Ensino Médio (BNCC-EM), como etapa final da Educação Básica, nos termos do artigo 35 da LDB, completando o conjunto constituído pela BNCC da Educação Infantil e do Ensino Fundamental, com base na Resolução CNE/CP n 2/2017, fundamentada no Parecer CNE/CP n ${ }^{\circ}$ 15/2017. Disponível em: http://portal.mec.gov.br/docman/dezembro-2018pdf/104101-rcp004-18/file. Acesso em: 21 dez. 2020.

BRASIL. Lei $n^{\circ}$ 13.415, de 16 de fevereiro de 2017. Altera as Leis $n^{\circ} 9.394$, de 20 de dezembro de 1996, que estabelece as diretrizes e bases da educação nacional, e 11.494, de 20 de junho 2007, que regulamenta o Fundo de Manutenção e Desenvolvimento da Educação Básica e de Valorização dos Profissionais da Educação, a Consolidação das Leis do Trabalho - CLT, aprovada pelo Decreto-Lei $n^{\circ} 5.452$, de $1^{\circ}$ de maio de 1943, e o Decreto-Lei $n^{\circ} 236$, de 28 de fevereiro de 1967; revoga a Lei $n^{\circ}$ 11.161, de 5 de agosto de 2005; e institui a Política de Fomento à Implementação de Escolas de Ensino Médio em Tempo Integral. Disponível em: http://www.planalto.gov.br/ccivil_03/_Ato2015-2018/2017/Lei/L13415.htm\#art3. Acesso em: 21 dez. 2020.

BRASIL. Lei no 11.684, de 2 de junho de 2008. Altera o art. 36 da Lei no 9.394, de 20 de dezembro de 1996, que estabelece as diretrizes e bases da educação nacional, para incluir a Filosofia e a Sociologia como disciplinas obrigatórias nos currículos do ensino médio. Disponível em: http://www.planalto.gov.br/ccivil_03/_Ato20072010/2008/Lei/L11684.htm. Acesso em: 10 out. 2019.

BRASIL. Lei n $^{\circ}$ 9.394, de 20 de dezembro de 1996. Estabelece as diretrizes e bases da educação nacional. Disponível em: http://www.planalto.gov.br/ccivil_03/leis//9394.htm. Acesso em: 21 dez. 2020.

CARMINATI, Celso João. Formação e didática do ensino da Filosofia. Revista Diálogo Educacional, v. 13, n. 38, p. 369-384, jan./abr. 2013.

CHAUÍ, Marilena. Iniciação à Filosofia: ensino médio. 2. ed. São Paulo: Ática, 2013. 
COTRIM, Gilberto; FERNANDES, Mirna. Fundamentos de Filosofia. 4. ed. São Paulo: Saraiva, 2016.

FERNANDES, Mirna. Filosofar na Escola. 2020. Disponível em: https://mirnafernandesweb.wordpress.com/author/mirgrafer/. Acesso em: 21 dez. 2020.

FRANCO, Eduardo Ferraz; FELÍCIO, Carmelita Brito de Freitas. Das desvantagens do livro didático para o ensino de Filosofia: a atualidade do pensamento de Nietzsche. In: Reunião Anual da SBPC, 63, 2011. Anais. Goiânia: UFG, 2011. Disponível em: http://www.sbpcnet.org.br/livro/63ra/conpeex/pibid/trabalhos-pibid/pibid-eduardoferraz.pdf. Acesso em: 2 out. 2019.

GIL, Antônio Carlos. Como elaborar projetos de pesquisa. 4. ed. São Paulo: Atlas, 2002.

GIL, Antônio Carlos. Métodos e técnicas de pesquisa social. 5. ed. São Paulo: Atlas, 1999.

INCONNTRI, Dora; BIGHETO, Alessandro Cesar. A Filosofia no Ensino Médio: um Desafio Filosófico e Pedagógico. Notondum Libro, n. 13, p. 29-34, 2009. Disponível em: http://www.hottopos.com/notand_lib_13/dora.pdf. Acesso em: 10 ago. 2019.

OLIVEIRA, Renato José. O livro didático de filosofia em foco. In: FRIGOTTO, Gaudêncio; CIAVATTA, Maria (org.). Ensino Médio: ciência, cultura e trabalho. Brasília: MEC/SEMTEC, 2004.

SILVEIRA, Thiago Coelho. Ensino de Filosofia no Ensino Médio: uma análise do livro Iniciação à Filosofia de Marilena Chauí. Cadernos do PET Filosofia, v. 6, n. 11, p. 7592, jan./jul. 2015. Disponível em:

https://revistas.ufpi.br/index.php/pet/article/view/3655/2767. Acesso em: 05 nov. 2020.

\section{Notas}

${ }^{1}$ Agradecemos ao Conselho Nacional de Desenvolvimento Científico e Tecnológico (CNPq) e ao Instituto Federal do Maranhão (IFMA) pelo financiamento da bolsa de pesquisa do discente do curso Técnico em Agronegócio, na forma subsequente, Wellington Oliveira Simões Nobre, que colaborou com o suporte operacional do processo de pesquisa.

\section{(c) $(1)(9)$}

This work is licensed under a Creative Commons Attribution-NonCommercial 4.0 International (CC BY-NC 4.0) 